\title{
Eco-art installation: experiential nature
}

\author{
R. G. Wakeland \\ New Mexico, USA
}

\begin{abstract}
Crowd reactions to a sculpture installation were collected at a 3-day open air event attended by 1,020 adults. Objectives of the installation were to raise awareness about air pollution and facilitate a group sculpture collaboration. Themes of scepticism, art appreciation, and further ideas for 3D environmental statements emerged. Artists' engagement with the natural world is explored.

Keywords: environmental sculpture installation, collaborative learning environment, air pollution, nature forms in art.
\end{abstract}

\section{Introduction}

A public event gave the artist/author the opportunity to install sculpture designed to measure particulate air pollution, and to facilitate a group sculpture. The sculpture's theory was that particulate air pollution collects on both plane and textile surfaces, as grey smudge, thus becoming observable. Junkyard metal objects, manufactured products, together with natural jute rope and fabric provided the media. Space and time inherent in the scenario provided the nonclassroom, collaborative learning environment.

\section{Literature review}

Pursuing a theory of outside-the-classroom art education pedagogy, Northern Illinois University professors and students directed a community mural project in 2009 with teenagers and adults. Consensus determined the subject: "Aztec narrative celebrating music" [1]. Mural painting and construction itself facilitated learning through problem-solving and knowledge-sharing. Like the writer's air pollution crusade, this endeavour also had a non-art motive: to test out collaborative learning and strengthen communication between the university and its surrounding neighbourhood [1]. 
A combined case study and life history of Ray Kass, a painter who derived inspiration from nature, evaluated another collaborative art event in 2009. Although the participants were university students, art workshops were held offcampus in artists' studios. Another artist in Japan collaborated with Kass as teacher. The landscapes surrounding the workshops, in Japan and West Virginia, served as the basis for Kass' reflection on nature and his experiential art teaching methodology [2]. Thus the groundwork and foundation has been laid for this endeavour to fuse nature with environmental commentary and group creativity.

\section{Inquiry, method and design}

The sculpture was designed on site to span available space and juxtapose the products of manufacturing with the natural world which suffers the environmental degradation process inherent in industry, Figure 1. The rope and coiled wire mimic human entanglement with both. The relatively unspoiled open air site in the Rocky Mountains (USA) had clean air and thus did not provide the optimum setting for measuring particulate air pollution. The 3-day time frame was also a drawback, as pollution accumulates on surfaces over time. However, the pristine setting provided in situ one half of the dichotomy/dynamic which the sculpture confronted: human interaction with and effect upon unspoiled nature. The other, industrial half was represented by the sculpture's junkyard objects, motor vehicles used to bring participants to the isolated site, and gasoline powered electric generators driving the music and light shows.

The artists' previous air pollution installations used fabric and empty laundry detergent bottles, together with a vinyl poster explaining Environment Protection Agency (EPA) air pollution data. The artist welcomed this opportunity for a longer and more complex installation and the chance to compete with performance art for attention. The event's non-profit organizers supported the sculpture with a grant.

The sculpture's effectiveness in raising awareness about air pollution and the success of the collaboration sculpture are both separate inquiries from the effectiveness of the sculpture as art object. However, the concrete art object, in task-based methodology, facilitates knowledge acquisition. The art object should be linked with recognizable forms in the environment. Cognitive strategies are integral to these instructional sequences [3]. In addition to the installation, Figure 1, two aluminium truck rims, 5 yards of fabric, and copper pipe were strewn around the site and announced as raw materials for a collaboration sculpture, if anyone were interested.

Attendees, having purchased their tickets and parked their cars, pledged to adhere to values of non-commercialism, leave no trace on the natural environment, interpersonal communication and self-expression. The art installation shared the environs with music and light show performances, pyrotechnics (fire and metal sculptures powered by propane), acrobats, jugglers, face painting, costumes, commedia dell'arte performances, and other visual art. The crowd was limited to 1,020 participants due to space limitations of the site. Most were adults; it was not advertised as a family gathering. 


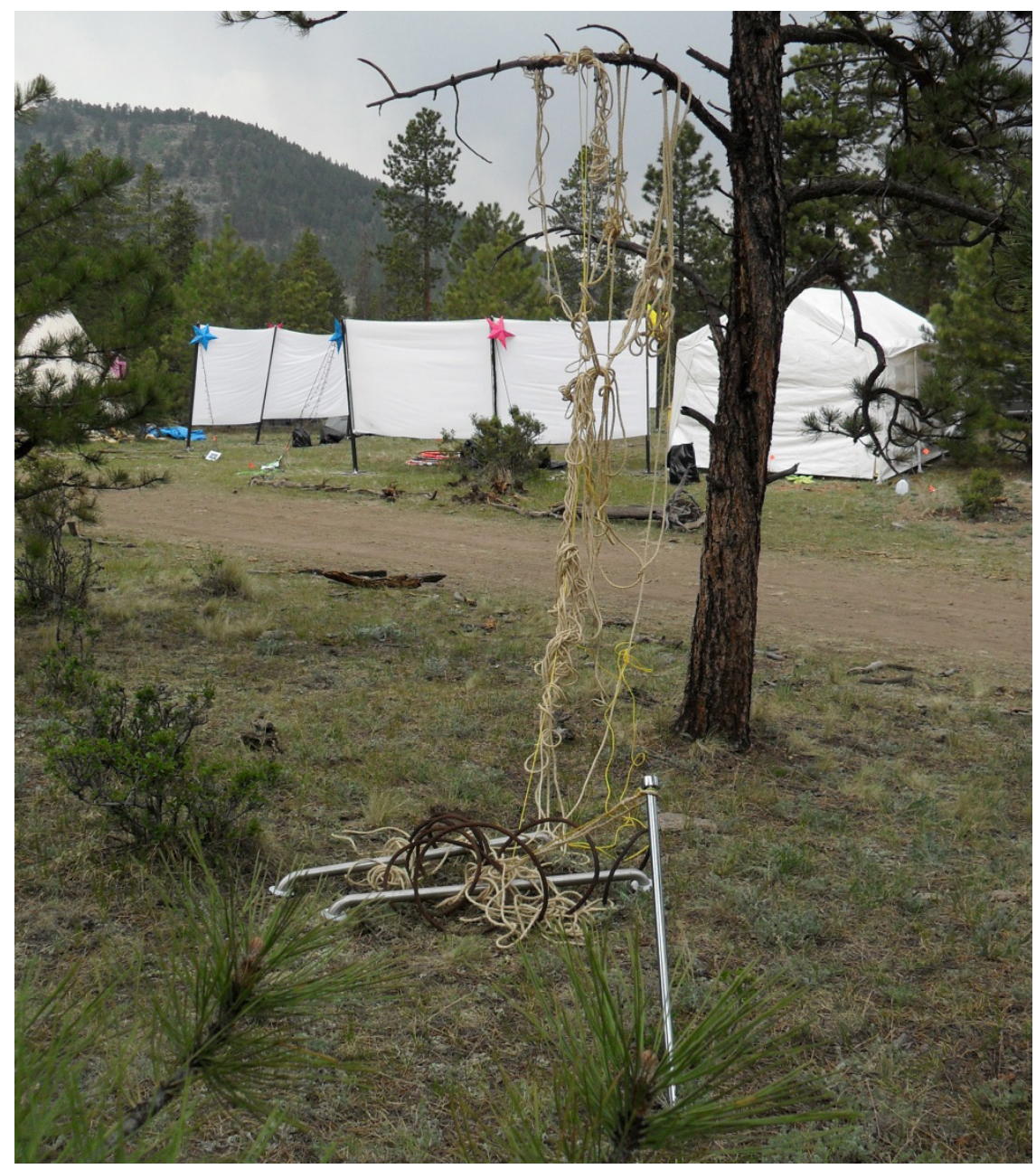

Figure 1: $\quad$ Sculpture to measure air pollution, by R.G. Wakeland, 2011. Stainless steel, steel cable, chrome plated steel junkyard objects, jute rope, polyester rope. Photo by Guy Mason.

Anonymous feedback responses from the crowd were sought in oral conversations. A sign in front of the sculpture said "sculpture to measure air pollution." The artist hung around the sculpture location for about four hours on each of two days, as well as the first day when she installed it, and also talked to people at other locations throughout the event. At the same time, passers-by were invited to use available materials and create another sculpture. A second observer, with a Ph.D. in health education and 25 years experience in adult education, spent a couple of hours at the installation gathering oral feedback. Responses from the board of directors were given in a discussion which they 
initiated, as part of their protocol for interviewing artists and evaluating granted art.

\section{Results and discussion}

Interspersed with comments about its message, the crowd responded that the installation in and of itself fulfilled its 3D art object, if narcissistic, function. Even at night, without any direct lighting, a few people noticed it. During the day, one woman said, "I don't understand about air pollution, but the sculpture is really beautiful." Another passer-by had the opposite reaction, saying "You call this sculpture, like you built the whole thing in 3-5 minutes, right?" While waxing disgruntled, this observer confirmed a spontaneous, even ephemeral quality of the sculpture.

The sculpture evoked concrete ideas for other art happenings. One suggested the two truck rims, situated as raw materials for the collaboration sculpture, be the source of a meltdown, "Are you going to burn those mag wheels? Magnesium wheels burn really hot." Another suggestion was for a sculpture to measure air pollution on a building, since such pollution weakens its structure and could cause it to collapse. Another suggestion was for a sculpture to measure ambient radiation, such as was released by the Fukushima nuclear power plant at the earthquake. To these comments, the artist responded with empirical litany, listing the melting temperature of aluminium, the deterioration of historic bronze sculpture in Rome from automobile exhaust, and docimeter technology.

Comments of scepticism included doubts that the sculpture could ever measure air pollution, asking how, and incredulity that it could ever work as claimed. This triggered lecture mode by the artist, explaining essentially the contents of the missing EPA poster, its maps, graphs and charts of particulate air pollution data and how the smudge manifests on buildings as streaks. Discussions on relative quality of mountain air versus city air ensued. However, this verbal lecture format departed from the goal/initiative to use the $3 \mathrm{D}$ object to convey the concept.

The second observer also attributed oral explanation and dialog to conveying the sculpture's air pollution message. She talked to about four other people, and reinforced the idea of measuring air pollution. Responses were that they liked the idea of using large found objects and uniting them with ropes and cable as an ecological statement.

Two members of the sponsoring organization board of directors provided similar feedback. They opined the sculpture fulfilled its art object and attentiongrabbing function, but needed a verbal or written explanation about air pollution. They were receptive to a future work, a series of four vinyl posters which the artist submitted after the grant deadline, showing pollution collecting efforts in Antarctica, and black streaks on buildings in urban environments. While the artist composed them in response to her literary muse, their inclusion would depart from the sculptural 3D emphasis and non-linear task based learning.

Throughout the weekend event, about six people expressed interest in creating a collaborative sculpture. A few said they would return to do so. 
However, no group effort ever materialized. Upon returning to the site to disassemble it, the artist discovered the truck rims sculpture, Figure 2. Whether it was an individual or group construction, it was a response to the invitation. Compared to the collaborations in the literature review, this effort represented a penultimate free-form model. Absent college courses, or a community center, involvement had free reign for three days among nature and industrial objects.

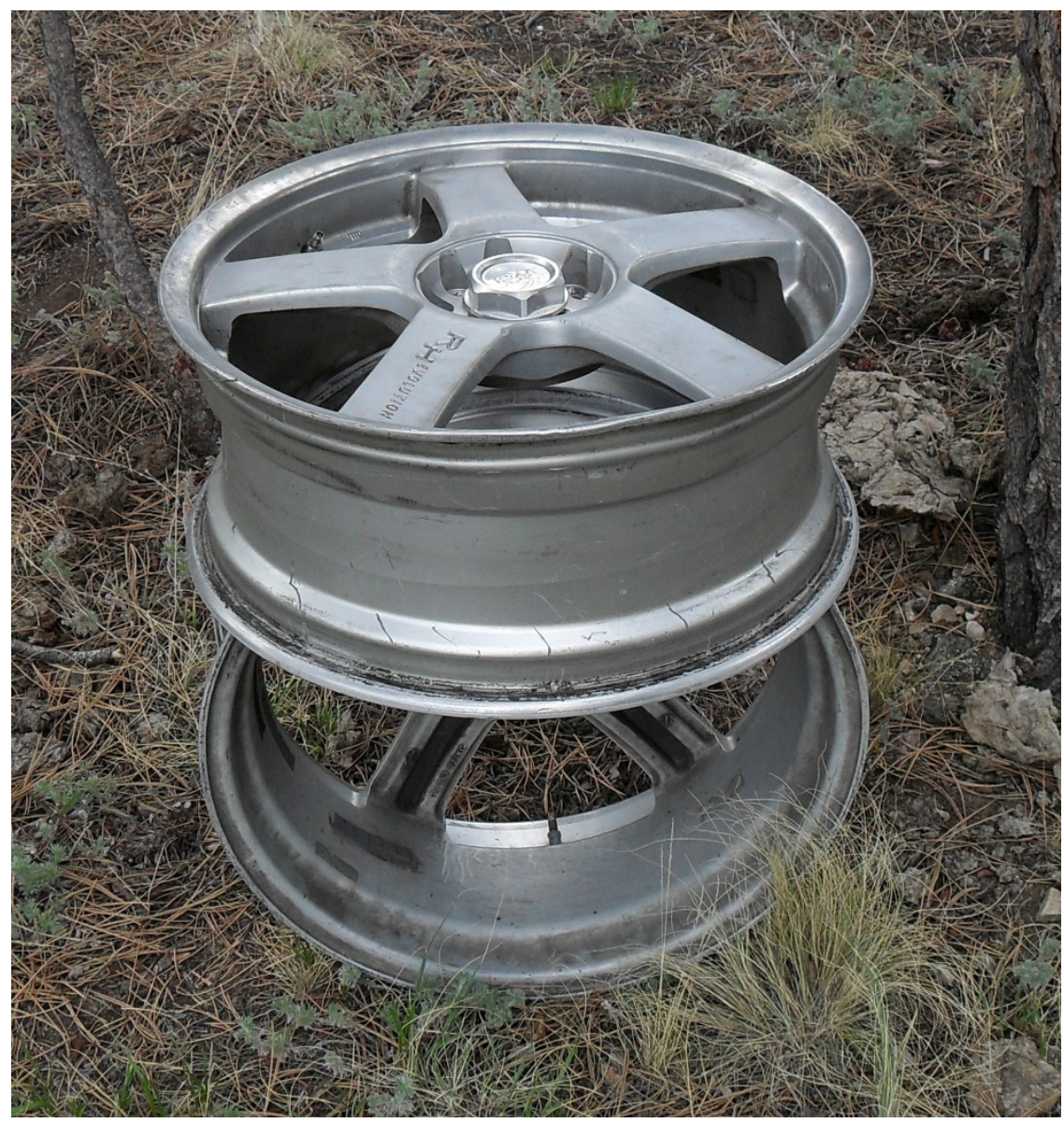

Figure 2: Collaboration sculpture, 2011. Aluminium junkyard truck tire rims.

Interpretation of nature and incorporation of natural forms in painting, as espoused by Kass [2] has philosophical threads in thousands of years of both western and Asian cultures. Natural forms are one aspect of art. The second and third aspects are wisdom and skill [4]. In, by and through rendering forms of nature, the artist synthesizes and expresses ideas, philosophy, religion, and metaphysics. But this representation is not bounded by realism. The character, and intangible facets and qualities of the natural world must be transferred to the 
artwork via the sensitivity and skill of the artist in order to properly manifest and communicate the ideas [4]. Imitation of nature is not inherent. Nature of the ancient philosophies no longer exists, having been irretrievably altered by the industrial revolution. But today in nature's remnants, still we can confront one aspect of our humanity: our interaction with nature.

\section{Conclusions}

While the sculpture failed as a stand-alone to measure particulate air pollution or to present a graphic image of it, it did evoke reactions of environmental trauma and eco-involvement. Fear of airborne nuclear radiation, paranoia of an environmentally-induced skyscraper collapse, and interaction with manufactured found-objects. The artist's inspiration wellspring of natural forms in the $21^{\text {st }}$ century extends beyond landscapes to eco-systems. And, an unfettered collaboration and experiential model surfaces, with no boundaries.

\section{References}

[1] Staikidis, Kryssi, Rex, E., Aulisa, G. and Lim, M. (2009). Learning outside the box: how Mayan pedagogy informs a community/university partnership. Art Education. 62(1):20-24.

[2] Sartorius, Tara Cady. (2009). Sight unscene. Arts \& Activities. 145(3):26-28.

[3] Gagne, R.M., and Driscoll, M.P. (1988). Essentials of learning for instruction. Englewood Cliffs, N.J.: Prentice Hall.

[4] Coomaraswamy, Ananda K. (1956). Transformation of nature in art. $2^{\text {nd }}$ ed. New York: Dover Publications. 